\title{
El fenómeno terrorista y su lógica de indefinición
}

\section{The terrorist phenomenon and its logic of uncertainty O fenómeno terrorista e sua lógica de indefinição}

\begin{abstract}
RESUMO
Desde a primeira definição legal do crime de terrorismo na Colômbia que teve lugar no código penal de 1980. Esse conceito participou de uma primeira ambiguidade da linguagem normativa, onde, em palavras do legislador penal foram descubertas as propriedades de uma situação de fato de periculosidade. Essa ambiguidade semântica originou um tipo de carência de limites de preços precisos na determinação desta forma especial normativa. Portanto, involve a interpretação jurídica, uma abertura expansionista do direito penal. Tendo em vista esta decantação. Corresponde ao legislador, na sua área de competência. Derramando clareza e segurança nesserárias sobre as ações que regularmente constituem em um tipo penal.
\end{abstract}

\section{PALAVRAS-CHAVES}

O terrorismo, A política criminal, Segurança jurídica, Incerteza jurídica.

\section{RESUMEN}

Desde la primera definición legal del delito de terrorismo en Colombia -que tuvo lugar en el Código Penal de 1980 - dicho concepto asistió a una primera vaguedad del lenguaje normativo, donde, en palabras del legislador penal, se describieron las propiedades de un supuesto fáctico de peligrosidad. Esta vaguedad semántica ha generado una especie de carencia de límites precisos en la determinación de esta especial forma normativa por lo que, en consecuencia, implica en la interpretación jurídica una apertura expansionista del Derecho Penal. Atendiendo a esta decantación, corresponde al legislador, en su ámbito de competencia, arrojar la claridad y certeza necesarias sobre las acciones que normativamente se instituyen en un tipo penal.

\section{PALABRAS CLAVE}

Terrorismo, Política criminal, Seguridad jurídica, Indeterminación jurídica.

\section{ABSTRACT}

Since the first legal definition of the crime of terrorism in Colombia -which took place in the Penal Code of 1980, the concept attended a first vagueness of normative language, where, in the words of criminal legislature, the properties of a factual assumption were described dangerousness. This semantic vagueness has created a kind of lack of precise boundaries in determining this particular standard form so consequently the legal interpretation implies an expansionary opening of criminal law. In response to this decantation, for the legislature in its field of competence, shed the necessary clarity and certainty about the actions that are normatively instituted a criminal offense.

\section{KEYWORDS}

Terrorism, Crime policy, Legal certainty, Legal uncertainty.

\section{JUAN FRANCISCO MENDOZA PERDOMO}

Abogado, Doctorante en Derecho. Docente Universidad Santo Tomás y Universidad Católica de Colombia. juanframendoza@gmail.com 
INTRODUCCIÓN

Los sistemas sociales (Luhmann, 1998) en sus diferentes procesos han pretendido alcanzar seguridad para sus ciudadanos, a partir de un conocimiento claro y fundado de las consecuencias de sus contactos en la práctica social. Uno de tales sistemas sociales es el jurídico, que mediante su propia complejidad y su entorno ha pretendido, en cada uno de sus subsistemas, conseguir la garantía de exactitud de los efectos de las relaciones que los individuos generalizan constantemente.

Esa garantía de exactitud toma, para el sistema del Derecho, el nombre de seguridad jurídica (Pérez Luño, 1991), que, definida abstractamente, dice de un principio de certidumbre, en favor de los ciudadanos, destinatarios de las normas jurídicas, quienes esperan que los efectos jurídicos de sus contactos fácticos, encuentren claridad y sedimento en las reglas de Derecho.

Al interior del sistema jurídico, el subsistema jurídico-penal ha ocupado su atención en el derrotero de la seguridad jurídica, buscando precisar la definición, el contenido y el alcance de categorías propias, como el delito y la sanción penal, que fácticamente, el primero, y contrafácticamente, el segundo, se realizan en el mundo. En este propósito, el Derecho Penal se ha servido del clásico principio de legalidad (Ferrajoli, 2005, pp. 33 y ss.), procurando una estabilidad conceptual, a partir del primer momento de intervención estatal, esto es, la confección de la ley, en el llamado momento legislativo (Fernández, 2002, pp. 216 y ss.).

De tan variada actividad en el momento legislativo, la construcción de las leyes es quizás el rol de mayor relevancia, por el deber asumido por el legislador de elaborar normas que concreten la pretendida seguridad jurídica.

Los tiempos actuales han ofrecido un reto al legislador para que muchas de las expectativas sociales de conducta de los ciudadanos lleguen a una concreción general, estable y abstracta, propia de las reglas de Derecho.

Dentro de este reto, un fenómeno de violencia sucesiva (González-Cussac, 2006, p. 71), con extensión al interior del sistema social de los Estados, como en el ámbito global, es el terrorismo; fenómeno que ha sido recepcionado por los legisladores de los Estados, como por la comunidad internacional, mediante normas de cobertura que propenden definirlo, y a través de normas de enjuiciamiento que intentan realizar el valor de justicia de las naciones para combatirlo.

En uno y otro caso, estas normas integran un sistema conceptual que utiliza una lógica dualista: terrorismo/antiterrorismo, que acusa una interesante deficiencia. Una deficiencia que se explica en la indefinición de la expresión terrorismo, la cual, sucedáneamente, se responde en el concepto de antiterror, como consecuencia y elemento de ese binomio lógico. 
Este artículo producto de una investigación científica, intentará explicar las razones de la indefinición que se acusa a esa lógica del prohibicionismo, en materia del terrorismo, y su respuesta institucional, concentrando este interés en el trabajo conceptual del momento legislativo.

\section{EL FENÓMENO DEL TERRORISMO Y LA POLÍTICA CRIMINAL}

Un fenómeno fáctico como el terrorismo, originado en el dato de la realidad, puede revestir muchas y disímiles definiciones desde los diferentes sistemas y subsistemas de una sociedad, o de un mundo global, si se quiere.

Como fenómeno de la realidad, resistirá apuestas de definición por la política, la economía, la historia, la antropología, la psicología, la sociología o el Derecho.

No obstante, ese dato fáctico del fenómeno del terror, cuando resulta lesivo de los valores e intereses del sistema social, sea por los daños directos que cause a estos, como por la situación de peligro que comprometa su funcionalidad, es asumido, en concreto, por la política criminal, que lo somete a un proceso de construcción conceptual, pasando por el tamiz de la política penal, para terminar estabilizado y generalizado en la norma jurídico-penal.

Un proceso institucional de construcción conceptual como el descrito, bajo el panorama de una política pública, como lo es la política criminal, inescindiblemente está vin- culado a la observación de los procesos sociales en los que se realizan los fenómenos nocivos, como al reconocimiento de los valores e intereses relevantes para la sociedad que se estiman lesionados.

Necesariamente, la observación de los procesos sociales y los valores relevantes está dotada, principalmente, del insumo descriptivo de la sociología que, como disciplina social, narra el proceso social con el lenguaje propio de su complejidad.

Es posible señalar que aun cuando otras disciplinas del saber informan al proceso de la política criminal, especialmente si se relacionan en forma directa con el dato fáctico, la sociología se constituye en el sector de mejor ofrecimiento valorativo de la realidad.

Pero tal afirmación, no puede elevar a la sociología al rango de disciplina justificadora y legitimadora de los conceptos de delito y pena, pues necesariamente deberá servirse de otros saberes interdisciplinarios, como que solo brinda una interpretación de los datos de la realidad que afectan a la sociedad (Elbert, 1995, p. 201).

Este papel de la sociología explica la relación necesaria, pero limitada, entre la política criminal y la dogmática penal, en la medida en que aquella suministra al Derecho Penal, sirviéndose de saberes como la sociología, el dato fáctico y el dato axiológico, una orientación hacia la prevención del delito; pero, a su turno, la dogmática penal sitúa unos límites a la política criminal, como barrera de 
contención al ejercicio del poder punitivo del Estado*.

Uno de estos límites es el principio de legalidad, que, inspirado en el de seguridad jurídica, pretende ser pauta irrenunciable, en el momento legislativo, como en el momento judicial, en los que el sistema penal desarroIla la más severa intervención de los derechos ciudadanos.

Es el escenario legislativo, en el que la garantía de legalidad adquiere destacada importancia, por cuanto en él, antes que habilitarse formalmente el ejercicio del poder punitivo, se agota la función limitadora del Derecho Penal, como verdadera actividad reductora (Zaffaroni, 2000, p. 414).

Con esto, el fenómeno del terrorismo, como dato de la realidad, suministrado por la política criminal al Derecho Penal, termina en esa decantación configurándose normativamente en un tipo penal al que el legislador, en su ámbito de competencia, debe dotar de la claridad y certeza necesarias, que permitan seleccionar, racional y limitadamente, las acciones que se conminan con pena (Fernández, 2002, p. 320).

Antes de observar cuáles han sido los datos de realidad y axiológicos, de los que se ha

* Se parte de una relación situacional entre política criminal y dogmática penal, que bien se define como una relación entorno-sistema, Cfr. Manuel Salvador Grosso García, El concepto del delito en el nuevo código penal. Una propuesta de interpretación desde el sistema de la teoría del delito, Bogotá, Ediciones Jurídicas Gustavo lbáñez, 1ae ed., 2003, pp. 321 a 327. servido el legislador para la configuración normativa del terrorismo, y que han propiciado el margen de indefinición conceptual, resulta necesario detenernos en la pauta de deber dirigida al legislador para la correcta elaboración de la ley penal, la que directamente ha inobservado cuando define la lógica dialéctica terrorismo/antiterrorismo.

\section{EL PRINCIPIO DE LEGALIDAD}

Dando por descontada la prevalencia de la dignidad humana, otro principio, como es el de legalidad, constituye el máximo fundamento del Derecho Penal, y por ende el criterio orientador de la interpretación de las normas jurídicas, cuando estas hacen al objeto de protección en materia penal, por estar ínsitas en ellas los valores que pretende tutelar el Estado mediante las medidas más enérgicas de control.

En la ciencia jurídica el principio de legalidad se define como el concepto estructural de la sujeción de las gestiones administrativas del Estado a la ley, siendo esta una relación de vinculación normativa del servidor público al cuerpo normativo regulador de las actividades. Es en el caso del Derecho Administrativo, en donde la legalidad adquiere mayor raigambre sujecional, por cuanto los sistemas constitucionales han entendido que el ámbito funcional de los servidores públicos debe estar enmarcado en la legalidad.

Pero a más de ser un referente de sujeción, la legalidad se revela como la manifestación de los estados de derecho que constitucio- 
nalmente rigen el ejercicio del poder público, a través del acatamiento de reglas de derecho objetivo, proferidas por los representantes de la colectividad.

En la práctica judicial la legalidad supone la más férrea sujeción del juez a la ley, sin comprender al operador judicial como un llano aplicador del derecho objetivo al margen de ejercicios hermenéuticos que le permitan interpretar la finalidad de los enunciados jurídicos.

A esa legalidad, referida como el superior principio en materia penal, interesa destacar la "estricta legalidad", que a contrario de la mera legalidad, en el planteo de Ferrajoli, define un principio cognoscitivo del Derecho Penal, dirigido al creador de la norma para que en su labor otorgue el sentido gramatical que el texto enseñe (Ferrajoli, 2005, pp. 375 y ss.). Ello en forma sustancial es lo que propone la pretendida teoría de la legislación, en su ocupación por la formulación de la ley*.

* La teoría de la legislación, a través de la utilización de un método "legislativo" en el que las categorías del "ser" y "deber ser" se encuentran en una relación de correspondencia recíproca, busca, trascendiendo las habituales metodologías jurídicas, invertir el método de la subsunción (correspondencia entre tipo legal y supuesto fáctico), para obtener una comunicación, mediante interpenetración entre la idea de derecho (deber ser y principios) y las situación fácticas (ser), en las cuales recíprocamente existe una apertura para la construcción de las normas jurídicas. Arthur Kaufmann, Filosofía del derecho, Universidad Externado de Colombia, 1999, pp. 54-58. Como función de esa actividad legislativa expresa Manuel Atienza, que la racionalidad busca la precisión de la ley, en orden a obtener una fluida comunicación entre la autoridad que dicta el derecho y sus destinatarios. Cfr. Manuel Atienza, Contribución a una teoría de la legislación, Civitas, Madrid, 1997, pp. 28-29.
Con ello, se perfila la legalidad como garantía de interpretación y aplicación de la norma penal, cuando quiera que el juez estará subordinado al estricto contenido de la ley, sin espacios para completar los textos errados o vacíos mediante interpretaciones desfavorables al destinatario del derecho (Fernández, 1999, p. 130).

En desarrollo de las funciones de garantía radicadas en la estricta legalidad surgen los objetivos, dirigidos al legislador, de construir las leyes incriminadoras asegurando la verdad y taxatividad de la descripción de las normas penales, entre las que se incluyen las prohibitivas y las permisivas.

La garantía de certeza jurídica como dimensión subjetiva del principio de seguridad jurídica consistirá: en la previsión para el ciudadano de lo mandado, lo prohibido y lo permitido; y en función de ese conocimiento, de la organización de sus propias acciones (Pérez, 2000 , p. 484). En materia sancionatoria se cumple la certeza cuando el legislador elabora tipos penales ciertos, claros y precisos en la descripción de los supuestos fácticos. En la medida en que el hecho antecedente de la sanción se indique con claridad sin aperturas a la incertidumbre, el ciudadano sabrá a qué atenerse, o dicho de otra manera, conocerá el curso de su acción u omisión frente a las sanciones penales. Esta previsión de conocimiento es la que caracteriza a la garantía de la ley penal cierta, conceptuada por un sector de la doctrina como la garantía de determinación de la ley (Mir Puig, 2002, p. 78), y 
por otra como la taxatividad (Jakobs, 1997, p. 89).

\section{EL PRINCIPIO DE TAXATIVIDAD Y LA CERTEZA JURÍDICA}

La taxatividad, inicialmente fundada en la certeza jurídica, hace a una garantía del principio de legalidad, y se convierte en un ideal de precisión de los enunciados prescriptivos, permisivos y descriptivos que comprende la regulación penal de cada Estado. Con ello, estimamos que el derrotero en el marco de la legalidad será la taxatividad como mejor expresión del axioma garantista del nullum crimen sine lege certa.

La taxatividad en términos de teoría jurídica se define como la exigencia de que los textos en que se vierten las normas sancionatorias describan con suficiente precisión qué conductas están prohibidas y qué sanciones se impondrán a quienes incurran en ellas (Ferreres, 2002, p. 21).

Es el notable arraigo del término de taxatividad, el que prefiere su utilización en materia penal, toda vez que refiere a la determinación de los tipos penales, como paradigma de descripción sancionatoria en el ámbito del Derecho sancionatorio estatal.

No obstante su relación funcional y su carácter técnico en la ciencia jurídica, la taxatividad y la reserva de ley, son principios con fundamentos y direcciones distintas en la disciplina jurídico-penal. Este es un enunciado jurídico, que utilizando las palabras de
Atienza corresponde a un "principio directriz" que como norma programática define qué enunciado jurídico es el que debe depositar el contenido y concepto del delito y de la pena*.

Consecuencia de esta directiva es la denominada por Ferrajoli mera legalidad, a través de la cual se estable el ámbito de competencia en la elaboración de la ley penal como una regla de distribución del poder público que atribuye al representante de los ciudadanos la elaboración de la ley sancionatoria mediante los procedimientos deliberativo y

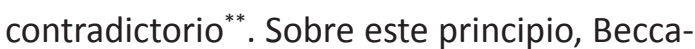
ria afirmó que "sólo las leyes pueden decretar las penas de los delitos; y esta autoridad debe residir punitivamente en el legislador, que representa a toda la sociedad regida por el contrato social" (Beccaria, 1994, p. 6).

Lo anterior explica el fundamento de la reserva de ley en el principio democrático, a contrario de la taxatividad que explica su justificación en los principios de certeza jurídica e imparcialidad, siendo este último una forma de igualdad en la aplicación de la ley.

De este modo, la taxatividad corresponderá, como principio, a un mandato de determinación, a través del cual la ley deberá definir de modo irrestricto las figuras delictivas, de

\footnotetext{
* También denominado por el mismo autor principio programático como norma dirigida a guiar el ejercicio normativo de los poderes públicos. Cfr. Atienza, Manuel, Las piezas del derecho, Teoría de los enunciados jurídicos, Barcelona, Ariel, 1996, p. 4.

** Que prescribe al juez solo concebir como delito lo que está llamado al legislador definir en el texto legal. Cfr. Derecho y razón, p. 378
} 
forma que solo quepan en el marco de la ley las conductas que se consideran punibles, y que dichas conductas se expresen en términos precisos, claros e inequívocos.

Esta exigencia de determinación de los textos de las normas sancionatorias se haya implícita en el principio de reserva de ley*, y de contera la taxatividad misma contribuye a incrementar en la labor legislativa el rigor de precisión en la elaboración de las reglas de Derecho. De hecho el ideal de claridad resulta consustancial a la función reguladora del Derecho, por manera que si el sistema jurídico pretende reglamentar las expectativas sociales de comportamiento deberá dirigirse a los destinatarios de dichas expectativas mediante un lenguaje caracterizado por la claridad.

No obstante la determinación como mandato, es indefectible afrontar un importante margen de indeterminación de las normas sancionatorias, ya advertido por la dogmática penal (Zaffaroni, p. 110), y la teoría jurídica (Alchourrón \& Bulygin, 1975), cuando se repara en el carácter parcialmente indeterminado del Derecho.

Esta indeterminación como problema explica el papel de guía de comportamiento de los principios jurídicos, cuando se reportan por los operadores judiciales dificultades en la aplicación de las reglas de derecho positivo.

\footnotetext{
* La correspondencia entre taxatividad y reserva de ley es advertida por Silva Sánchez. Cfr. Aproximación al derecho penal contemporáneo, Barcelona, Bosch, 1992, p. 257.
}

Seguramente en materias como el Derecho Administrativo o el Derecho Privado la utilización práctica de los principios directivos en la solución de la indeterminación de las formulaciones normativas resulte de irreparable rendimiento en la solución de los casos, pero en Derecho Penal la existencia y usanza de los principios, concebidos bajo la nominación de normas rectoras, merece especial atención, cuando quiera que la exigencia de precisión se traduce en el control mínimo del contenido de las normas prohibitivas o permisivas del Derecho Penal, constituyéndose en un marco fundamental para su significación, que se materializa en su interrelación y aplicación (Fernández, 1991, p. 95).

No obstante el derrotero de taxatividad, debe reconocerse la posibilidad de redacción de textos jurídicos con un importante margen de indeterminación, lo que abre una necesaria intervención interpretativa del dispensador de justicia, ante la reprochable interpretación exegética del texto normativo, a la manera en que el pensamiento ilustrado pretendía que los cuerpos normativos fueran tan precisos en su redacción que redujeran la labor judicial a una llana aplicación mecánica de la ley por parte del juez.

Una apertura de esta característica, es desde luego, generadora de costos importantes para la seguridad jurídica, los cuales solo pueden ser reducidos pero no suprimidos.

Así, el principio de legalidad, a través de la taxatividad, será, entonces, el sedimento de la libertad del ciudadano, pues solo las nor- 
mas con claros límites del lenguaje normativo permitirán a los destinatarios del Derecho elegir, con conocimiento de la ley, si se siguen o no las prohibiciones penales.

Más adelante observaremos si la taxatividad es alcanzada en el lenguaje normativo del terrorismo, si existe algún margen de indeterminación, o se evidencia una problemática indefinición, más allá de lo normativo.

\section{LA INDEFINICIÓN DEL CONCEPTO JURÍ- DICO DE TERRORISMO}

Pese al derrotero de taxatividad, o determinación exhaustiva del concepto legal de terrorismo, el legislador jurídico-penal desde la primera definición legal de este delito*

* $\quad$ Art. 187. Terrorismo. Modificado por el Decreto 2266 de 1991, Art. 4. El que provoque o mantenga en estado de zozobra o terror a la población o a un sector de ella, mediante actos que pongan en peligro la vida, la integridad física o la libertad de las personas o las edificaciones o medios de comunicación, transporte, procesamiento o conducción de fluidos o fuerzas motrices, valiéndose de medios capaces de causar estragos incurrirá en prisión de diez (10) a veinte (20) años y multa de diez (10) a cien (100) salarios mínimos mensuales, sin perjuicio de la pena que le corresponda por los demás delitos que ocasionen con este hecho.

Si el estado de zozobra o de terror es provocado mediante llamada telefónica, cinta magnetofónica, video, casete o escrito anónimo, la pena será de dos (2) a cinco (5) años y la multa de cinco (5) a cincuenta (50) salarios mínimos mensuales. Otro tanto hizo el legislador extraordinario en Colombia mediante el Decreto 180 de 1988, con el cual exacerbó la omnipresencia normativa del terrorismo en el sistema penal. Esto por medio de la creación de un capítulo I destinado a los delitos de terrorismo entre estos: terrorismo, auxilio a las actividades terroristas, omisión de informes sobre actividades terroristas, exigencia o solicitud de cuotas para terrorismo, instigación o constreñimiento para ingreso a grupos terroristas, instigación al terrorismo, incendio, destrucción o daño de nave, aeronave o medio de transporte por acto terrorista, disparo de arma de fuego y empleo de explosivos contra vehículos, tenencia, fabricación, tráfico y uso de armas o sustancias tóxicas, empleo o lanzamiento de sustancias u objetos peligrosos, fabricación y tráfico de armas y municiones de uso privativo
-Código Penal de 1980-, asistió a una primera vaguedad del lenguaje normativo, representada en las palabras utilizadas por el legislador penal que describió las propiedades de un supuesto fáctico de peligrosidad, vertido en un enunciado jurídico, lo que ha generado una especie de carencia de límites precisos de esta especial forma normativa.

Estos "espacios de penumbra", propios de la vaguedad, identifican un grupo de casos en los que los límites del lenguaje normativo no resultan claramente observables y, en consecuencia, la imprecisión cobra una graduación interpretativa que se revelaría, cuantitativamente en casos a los que no pueda aplicarse el Derecho, como afirmara Nino (1999, p. 264).

En el ámbito jurídico penal la vaguedad se encuentra reflejada en el concepto, contenido y alcance de algunos elementos del tipo legal, particularmente en los conocidos elementos descriptivos del tipo, a través de los cuales se describen objetos del mundo real, que como conceptos pueden ser tomados del lenguaje cotidiano por poseer una referencia a la realidad cognoscible**

de las fuerzas militares o de Policía Nacional, corrupción de alimentos y medicinas, instrucción y entrenamiento, utilización ilícita de equipos transmisores o receptores, administración de recursos, intercepción de correspondencia oficial, y utilización ilegal de uniformes e insignias.

** Como un paradigma del conocimiento de esta clase de objetos descritos por la norma penal se plantea la fórmula de la "valoración paralela en la esfera del profano" que fuera propuesta por Mezger siguiendo a Binding, Cfr. Jescheck, Hans-Heinrich (2003). Tratado de derecho penal, p. 316. 
Otro tanto hace a la vaguedad de algunos elementos normativos del tipo, que como conceptos dotados de contenido normativo, no resultan de fácil aprehensión para el destinatario de la norma, o se prestan a diferentes, y no convergentes, interpretaciones, por lo que debe acudirse a la idea de derecho que pueda concurrir en el ámbito de conocimiento de un ciudadano común.

Destacado es el caso de las actuales técnicas de tipificación en los delitos de peligro, abstracto, como el de terrorismo, en los cuales se utilizan elementos descriptivos que corresponden a alocuciones abiertas del lenguaje, que aun cuando explican expresiones semánticas, pertenecientes al lenguaje común, generan en la interpretación jurídica una apertura expansionista del Derecho Penal.

Es el caso de expresiones como "estado de zozobra o terror en la población", o "actos que pongan en peligro la vida, la integridad física o la libertad de las personas o las edificaciones o medios de comunicación, transporte, procesamiento o conducción de fluidos o fuerzas motrices", que al rompe invitan a sustituir la palabra del legislador con la introducción de términos valorativos, que constituyan la puerta abierta a prácticas sustancialistas, en las cuales los excesivos juicios de valor dotan de una manida discrecionalidad al operador jurídico para delimitar las fronteras del concepto y contenido del delito, ingresando con ello a la contracara de la estricta legalidad, esto es, a decidir, por boca del juez, qué debe comprender el concepto de delito y qué debe proteger el Derecho Penal.

No es fácil para el legislador alcanzar la precisión del lenguaje en los textos normativos, pero lo cierto es que resulta particularmente forzoso obtener una comprensión amplia del dato axiológico que pretende regular la abstracción del enunciado jurídico, sobre todo en lo que hace a las posibles excepciones en la aplicación de la ley en esos casos dudosos que no pueden ser subsumidos.

\section{EL DATO DE LA SOCIOLOGÍA EN LAS CA- TEGORÍAS JURÍDICAS DEL TERRORISMO}

Si las voces utilizadas por el legislador en el texto de la ley, están informadas de valor axiológico, tomado de la información empírica de cada sociedad, en su propio contexto, resulta lógico afirmar que las acciones que se estiman punibles, se correspondan con una hipótesis de la realidad; es decir, que la norma penal, en efecto lleva al lenguaje normativo fenómenos, como comportamientos de la realidad.

De tal manera, que el terrorismo constituye un fenómeno más de la realidad, que ha sido dotado de conceptos propios de la sociología, que en su función epistemológica, ha conseguido un concepto legitimador, partiendo del contexto de sociedad y las características del fenómeno fáctico.

El decaimiento de la modernidad, y la con- 
secuente introducción del movimiento de la posmodernidad, provocaron un cambio de paradigma en la sociología, generando una opinión catastrófica (Grosso, 2001, p. 39) y negativa en muchos de los ámbitos de la sociedad*.

Esta sociología se ha apropiado de conceptos como globalización, emancipación, individualidad, levedad, unificación de espacio/ tiempo, flexibilidad y riesgo, que le han servido para caracterizar y definir los procesos sociales de nuestra actualidad, así como los fenómenos que al interior de estos se desarrollan.

Un nuevo concepto que en forma reductiva ha imbricado a la sociedad y sus fenómenos es el de "sociedad de riesgo global", acuñado por el sociólogo alemán Ulrich Beck (2002), y mediante el cual se pretende no solo fundamentar y legitimar, sino reconceptualizar los sistemas sociales y los riesgos que les amenazan.

A tal imbricación no escapan las categorías del sistema jurídico, menos aun la del subsistema del Derecho Penal. Ello es demos-

* "La principal técnica de poder es ahora la huída, el escurrimiento, la elisión, la capacidad de evitar, el rechazo concreto de cualquier confinamiento territorial y de sus engorrosos corolarios de construcción y mantenimiento de un orden, en la responsabilidad por sus consecuencias y de la necesidad de afrontar sus costos", con estas palabras define claramente la llamada "modernidad líquida" el sociólogo polaco Zygmunt Bauman a la sociedad actual. Cfr. Zygmunt Bauman, Modernidad líquida, Buenos Aires, Fondo de Cultura Económica de Argentina, 2009, p. 17. Otros sociólogos han definido esta nueva época, como "constelación postnacional", "modernidad reflexiva", o "segunda modernidad". trativo, mediante la asunción de conceptos como seguridad, riesgo, responsabilidad o culpabilidad, respecto de los cuales se ha querido ocupar la sociología, al paso que se aceptan los aportes de esta por la dogmática penal actual (AAVV, 2009, pp. 23-58). La significación de ciertos bienes jurídicos, como intereses que a los que el Derecho Penal dispensa protección; el contenido de ciertas figuras delictivas, y muchas palabras del lenguaje normativo, han sido influenciados en su formación, como en su interpretación por la ciencia social.

Esto debe resultar entendible si se piensa que la política criminal, como política pública, debe utilizar a la sociología como una de las varias disciplinas, que le son útiles en esa verificación del contexto de la realidad, necesaria para llevar muchos conflictos sociales al Derecho. Sin embargo, debe advertirse que en algunos campos del Derecho Penal se presenta una suerte de sustitución conceptual de conceptos de Derecho Penal por los de la sociología o, si se quiere, una especie de dotación conceptual de esta disciplina social al lenguaje jurídico-penal, que ha generado las contradicciones propias de la insuficiencia que producen los conceptos difusos (Grasso, 2006, pp. 33-34).

Ello es demostrable cuando el concepto de seguridad, bien jurídico contra el que atenta el terrorismo, se define a partir de la analogía del significado de la persona del terrorista, como: moradores, como extraños ubicuos en el tiempo/espacio, generador de un 
"miedo ambiente", el que genera una política del miedo cotidiano (Bauman, 2009, pp. $101,102,115)$. Al tiempo, cuando se quiere definir los que afectan la seguridad, se utilizan los conceptos de riesgo y de peligro, los que se pretenden homologar, sin proporciones, al concepto de delito; así lo hace Beck, cuando afirma: "Los nuevos peligros están eliminando los cimientos convencionales de seguridad" (Beck, 2002, p. 37).

A este reflejo analógico se ha conducido también el concepto de "terrorismo", como fenómeno fáctico que lesiona la seguridad pública, y respecto del cual -señalan las políticas públicas- deben adoptarse medidas antiterroristas.

Las medidas antiterroristas, desde luego, utilizan también la lógica del lenguaje de la analogía, cuando se expresa que debe prevalecer la seguridad sobre la libertad, que para conseguir libertad se requiere seguridad y que la sociedad como un cuerpo supremo, e imagen simbólica de la comunidad, debe ser "purificada de toda sustancia extraña e indigerible, con todos los puntos de acceso, cuidadosamente vigilados, controlados y protegidos..." (Bauman, pp. 194-195).

Es esta lógica contrafáctica la que se ha permitido definir el terrorismo, utilizando la significación de la respuesta estatal como modelo de definición. Así, la dinámica de interacción entre la acción terrorista y la reacción estatal es la que resulta más útil para comprender la configuración del terrorismo (Cancio, 2010, p. 68).

Aparecen en esta configuración conceptos como el de miedo, que al recoger la significación de la zozobra y el terror, como afectación de la seguridad de la población, es apropiado por la sociología y los medios de comunicación, cuando se encargan desde sus ópticas de determinar la gravedad y prominencia del riesgo en que devienen los miedos. Es allí en donde la sociología define las emociones provocadas por el miedo, que hacen descuidar los cálculos de probabilidad de riesgo, y los ciudadanos terminan por ser objeto de este impacto (Sunstein, 2009, p. 127). El miedo será un elemento desagregado de la definición legal de terrorismo, que terminará encontrando significación empírica por la sociología.

A su paso, el concepto de "culpabilidad", inmanente al Derecho Penal, en su configuración ha sido erosionado en su contenido y alcance, al señalarse la pérdida de eficacia en el caso del terrorismo. Afirma Pawlik que un concepto como el de culpabilidad, tan caro a la dogmática jurídico-penal, parece carecer de relevancia en la determinación de responsabilidad del delito de terrorismo (Pawlik, 2010, pp. 160 y ss.), lo que ha sido un terreno allanado para el momento judicial.

Queda entonces claro que la indefinición, con el proceso dialéctico terrorismo/antiterrorismo, sufre una incertidumbre conceptual (González, 2002, p. 19) que habilita al legislador y al juzgador, en sus diferentes 
momentos funcionales, para conceptuar y dar contenido a las categorías positivas del Derecho Penal, así como para fijar sus alcances.

Si ese proceso de interacción define la heurística con que se administra el fenómeno terrorista, las medidas legislativas y policiales adoptadas para contrarrestarle serán explicativas de una forma de principio de precaución, en donde la definición jurídicopenal de terrorismo se vale de la misma base empírica de la heurística. Se trata, entonces, de un sistema argumental cerrado en donde el Derecho estará preso de la comprensión contrafáctica.

Tal problemática solo se explica por el quehacer de la sociología, cuando en la búsqueda de establecer conceptos que le son extraños a su carácter "relativo y transitorio", se vale de medios, de suyo, inestables como discutibles, como la intuición, la literatura o los sentimientos de los investigadores, que a la postre pueden ser generadores de una auténtica anarquía epistemológica*.

A contrario, el fenómeno terrorista y su enfrentamiento, pueden ser tratados con ajuste al Estado de derecho, y sin afectar los conceptos, propios del Derecho Penal, los cuales, como reclama Pawlik, deben ser llamados por su nombre (p. 179). Desde luego será posible, en ese Estado de derecho,

\footnotetext{
* Con una crítica vehemente desde la criminología, Cfr. Carlos Alberto Elbert, Manual básico de criminología, p. 201.
}

alcanzar conceptos jurídicos estables, que permitan definir con certeza lo que deben entender los individuos del sistema jurídico, por delito de terrorismo. Al efecto, la sociología debe suministrar el dato de realidad sin que el mismo se subrogue en el contenido y concepto de las categorías del Derecho Penal.

\section{REFERENCIAS}

AAVV (2009). Derecho penal en la sociedad del riesgo. Bogotá: Ibáñez.

Alchourrón, C. \& Bulygin, E. (1975). Introducción a la metodología de las ciencias jurídicas y sociales. Buenos Aires: Astrea.

Atienza, M. (1996). Las piezas del derecho, teoría de los enunciados jurídicos. Barcelona: Ariel.

Atienza, M. (1997). Contribución a una teoría de la legis/ación. Madrid: Civitas.

Bauman, Z. (2009). Modernidad líquida. Buenos Aires: Fondo de Cultura Económica de Argentina.

Beccaria, C. (1994). De los delitos y de las penas. Bogotá: Temis.

Beck, U. (2002). La sociedad del riesgo global. Madrid: Siglo XXI.

Cancio Meliá, M. (2010). Los delitos de terrorismo: estructura típica e injusto. Madrid: Editorial Reus. 
Carrasquilla, J. F. (1999). Principios y normas rectoras del derecho penal. Introducción a la teoría del delito en el estado social y democrático de derecho. Segunda edición. Bogotá: Leyer.

Carrasquilla, J. F. (2002). Derecho penal liberal de hoy. Introducción a la dogmática axiológica jurídico-penal. Bogotá: Edicons Jurídicas Gustavo Ibañez.

Elbert, C. A. (1995). Manual básico de criminología. Bogotá: Temis.

Ferrajoli, L. (2005). Derecho y razón. Teoría del garantismo penal. Séptima edición. Madrid: Trotta.

Ferreres Comella, V. (2002). El principio de taxatividad en materia penal y el valor normativo de la jurisprudencia. Una perspectiva constitucional. Madrid: Civitas.

González Calleja, E. (2002). Políticas del miedo: un balance del terrorismo en Europa. Barcelona: Biblioteca Nueva.

González Cussac, J. L. (2006). El derecho penal frente al terrorismo. En J. L. Gómez Colomer \& J. L. González Cussac (coords.), Terrorismo y proceso penal acusatorio. Valencia: Tirant Lo Blanch.

Grosso García, M. S. (2001). Dos estudios sobre la nueva teoría normativista del delito. Bogotá: Ibáñez.
Grosso García, M. S. (2003). El concepto del delito en el nuevo código penal. Una propuesta de interpretación desde el sistema de la teoría del delito. Primera edición. Bogotá: Ediciones Jurídicas Gustavo Ibáñez.

Grosso García, M. S. (2006). ¿Qué es y qué puede ser el "derecho penal del enemigo"? Una aproximación crítica al concepto. En M. Cancio Meliá \& C. Gómez-Jara Díez (coords.), Derecho penal del enemigo, el discurso penal de la exclusión. Vol. 2 (pp. 33-34). Buenos Aires: Montevideo.

Jesckeck, H. H. (2003). Tratado de derecho penal: parte general. Granada: Editorial Comares.

Jakobs, G. (1997). Derecho penal, parte general. Segunda edición. Madrid: Marcial Pons.

Kaufmann, A. (1999). Filosofía del derecho. Universidad Externado de Colombia.

Luhmann, N. (1998). Sistemas sociales. Lineamientos para una teoría general. BarceIona-México: Anthropos, Universidad Iberoamericana.

Mir Puig, S. (2002). Derecho penal, parte general. Quinta edición. Barcelona.

Nino, C. S. (1999). Introducción al análisis del derecho. Novena edición. Barcelona: Ariel.

Pawlik, M. (2010). La libertad institucionalizada. Madrid: Marcial Pons. 
Pérez Luño, A. (1991). La seguridad jurídica. Sunstein, C. (2009). Leyes del miedo. Madrid: Barcelona: Ariel. Katz.

Perez Luño, A. E. (2000). Seguridad jurídica. Zaffaroni, E. R. (2000). Derecho penal, parte En E. Garzón Valdes, F. Laporta, El derecho y general. Buenos Aires: Ediar. la justicia. Madrid: Trotta.

Sánchez, S. (1992). Aproximación al derecho penal contemporáneo. Barcelona: Bosch. 